\title{
OPTIMASI ARUS BERKAS ELEKTRON DAN PENENTUAN HARGA PARAMETER DALAM BEJANA GENERATOR PLASMA
}

\section{ELECTRON BEAM CURRENT OPTIMATION AND PARAMETER VALUES DETERMINATION IN PLASMA GENERATOR CHAMBER}

\author{
Agus Purwadi \\ Pusat Sains dan Teknologi Akselerator, BATAN \\ Jl. Babarsari Kotak Pos 6101 Ykbb Yogyakarta 55281 \\ e-mail: agus.p@batan.go.id
}

Diterima 02 Mei 2014, diterima dalam bentuk perbaikan 17 Juni 2014, disetujui 23 Juni 2014

\begin{abstract}
ABSTRAK
OPTIMASI ARUS BERKAS ELEKTRON DAN PENENTUAN HARGA PARAMETER DALAM BEJANA GENERATOR PLASMA. Bejana Generator Plasma (BGP) merupakan salah satu komponen utama unit perkakas Sumber Elektron Katoda Plasma (SEKP), besar arus berkas elektron plasma dalam BGP akan mempengaruhi perolehan kualitas arus berkas elektron pada perkakas SEKP. Telah dilakukan optimasi arus berkas elektron plasma dan penentuan harga parameter plasma dalam BGP. BGP dibuat dari bahan SS 304 bentuk silinder dengan diameter $4,00 \mathrm{~cm}$ dan panjang $48,75 \mathrm{~cm}$. Optimasi arus berkas elektron plasma dalam BGP dilakukan pada tegangan keluaran ignitor $12 \mathrm{kV}$ untuk sistem IDPS (Ignitor Discharge Power Supply) dan tegangan anoda pemercepat $1 \mathrm{kV}$ untuk sistem ADPS (Arc Discharge Power Supply), sedang tekanan gas kerja/gas argon divariasi dari orde 10-4 $\mathrm{mbar}\left(P_{A r}=4,4 \times 10^{-4} \mathrm{mbar}\right)$ sampai dengan orde 10-3 $\mathrm{mbar}\left(P_{A r}=2,4\right.$ $\times 10^{-3}$ mbar). Dari hasil eksperimen telah diperoleh besar arus berkas elektron optimum sebesar laDPS-opt.= 164,80 A pada tekanan gas argon $P_{A r}$ orde $10^{-4}$ mbar dan parameter plasma yang diperoleh dalam BGP adalah kerapatan elektron plasma $n_{e}=\left(1,684 \times 10^{20}\right)$ partikel $/ \mathrm{m}^{3}$, suhu elektron plasma $T_{e}=\left(9,788 \times 10^{4}\right) \mathrm{K}=8,44$ $\mathrm{eV}$, panjang Debye $\lambda_{D} \approx 0,17 \mathrm{~mm}$ dan tebal sheath plasma $d_{s} \approx 6,00 \mathrm{~mm}$.
\end{abstract}

Kata kunci : Plasma, lucutan arc, kerapatan plasma, suhu plasma, tebal selubung plasma.

\begin{abstract}
ELECTRON BEAM CURRENT OPTIMATION AND PARAMETER VALUES DETERMINATION IN PLASMA GENERATOR CHAMBER. Plasma Generator Chamber (PGC) is a main component of the Plasma Chatode Electron Source (PCES) device, the value of plasma electron beam current in PGC will influence in obtaining the electron beam current quality of PCES device. It has been carried out the plasma electron beam current optimation and plasma parameter values determination in the PGC. PGC is made of SS-304 cylinder shaped with diameter of $4.00 \mathrm{~cm}$ and length of $48.75 \mathrm{~cm}$. The plasma electron beam current optimation in PGC is carried out on ignitor output voltage of $12 \mathrm{kV}$ for Ignitor Discharge Power Supply (IDPS) system and acceleration anode voltage of $1 \mathrm{kV}$ on Arc Discharge Power Supply (ADPS) system, then the work gas pressure/argon gas is varied from $10^{-4}$ mbar orde $\left(P_{A r}=4 \times 10^{-4}\right.$ mbar) up to $10^{-3}$ mbar orde $\left(P_{A r}=2.4 \times 10^{-3}\right.$ mbar). From the experiment result it has been obtained that the values of optimum electron beam current is $I_{\text {ADPS-Opt. }}=164.8 \mathrm{~A}$ at the argon gas pressure of $P_{\text {Ar }}$ in the orde of $10^{-4} \mathrm{mbar}$, and the plasma parameters obtained in the PGL are the plasma electron density $n_{e}=\left(1,684 \times 10^{20}\right)$ particles $/ \mathrm{m}^{3}$, plasma electron temperature $T_{e}=\left(9.788 \times 10^{4}\right) \mathrm{K}=8,44 \mathrm{eV}$, Debye length $\Lambda_{D} \approx 0.17 \mathrm{~mm}$ and the plasma sheath thickness $d_{s}$ $\approx 6.00 \mathrm{~mm}$.
\end{abstract}

Keywords :Plasma, arc discharge, plasma density, plasma temperature, the plasma sheath

\section{PENDAHULUAN}

Bejana Generator Plasma (BGP) merupakan komponen utama dari unit peralatan Sumber Elektron Katode DPlasma (SEKP). SEKP adalah suatu pembangkit berkas elektron yang mana berkas elektron dibentuk oleh adanya ekstraksi elektron dari BGP. SEKP dapat menghasilkan keluaran berkas elektron berpenampang luas dengan kerapatan arus tinggi hingga mencapai $100 \mathrm{~A} / \mathrm{cm}^{2}$ (lebar pulsa dari nanodetik hingga millidetik) telah dapat 
J. Iptek Nuklir Ganendra

Ganendra Journal of Nuclear Science and Technology

Vol. 17 No. 2 Juli 2014: $75-82$

diaplikasikan dalam teknologi radiasi, dalam modifikasi permukaan untuk struktur materi, dalam pemompaan media aktif gas laser dan dalam bidang-bidang lainnya (1-4). Tujuan dari penelitian ini adalah mengoptimalkan besar arus berkas elektron dalam BGP yakni arus lucut berkas electron plasma yang terbentuk akibat adanya perbedaan potensial antara katoda (sistem elektroda ignitor/pemicu) dengan anoda pemercepat pada sistem ADPS (Arc System Power Supply) yang untuk selanjutnya arus tersebut dinotasikan dengan $I_{\text {ADPS. }}$. Optimasi besar arus lucut berkas elektron $I_{\text {ADPS }}$ dilakukan dengan cara memvariasi gas kerja/gas argon untuk berbagai harga tekanan gas argon (divariasi dari $10^{-4}$ sampai dengan $10^{-3} \mathrm{mbar}$ ). Menurut literatur, besar arus lucut berkas elektron $I_{\text {ADPS }}$ dalam BGP pada tekanan gas argon antara $10^{-4}$ sampai dengan $10^{-3}$ mbar adalah $I_{A D P S}=(50-200)$ A dengan lebar pulsa sebesar $\tau=100 \mu \mathrm{s}^{(5)}$. Parameter plasma dapat ditentukan atas dasar hasil perolehan besar arus $I_{\text {ADPS }}$ (arus Arc Dischage Power Supply) optimum dalam BGP. Dengan diperolehnya harga arus $I_{\text {ADPS }}$ optimum di dalam BGP diharapkan arus tersebut setelah terekstraksi dari sistem grid dan dipercepat oleh tegangan eksternal juga akan menjadi arus berkas elektron perkakas SEKP optimum, dalam arti dapat dicapai arus berkas elektron dengan penampang berkas luas dan berkerapatan tinggi sesuai dengan yang diharapkan (dapat terkontrol). Selain bergantung pada besar tegangan pemercepat eksternal, bentuk geometri dan ukuran grid, arus berkas elektron pulsa dalam BGP sangat dominan pengaruhya dalam penentuan kualitas arus berkas elektron unit perkakas SEKP (6-7).

Plasma dalam BGP dapat terbentuk setelah adanya spot plasma di permukaan katoda tembaga pada modul elektroda pemicu dan baru dilanjutkan lucutan plasma akibat adanya beda potensial antara katoda (sistem elektroda) dengan anoda pemercepat (grid yang dipasang pada dinding BGP). Timbulnya spot plasma tersebut dipasok oleh adanya sumber daya discharge ignitor (Ignitor Discharge Power Supply/IDPS) orde puluhan kV, sedang terjadinya plasma dipasok oleh adanya sumber daya arc discharge (Arc Discharge Power Supply/ADPS) pada orde (800-1000) volt.

Elektron plasma di dalam BGP, pada bagian permukaan/batas plasma ditarik menuju ke dinding anoda (sistem grid) oleh tegangan anoda pemercepat dengan menempuh jarak sejauh tebal selubung /sheath plasma, selanjutnya arus berkas elektron yang terekstraksi dari sistem grid akan dipercepat menggunakan tegangan pemercepat eksternal orde ratusan kilo-volt (kV) menuju target melalui jendela (window foil) pada bejana vakum terluar. Dalam eksperimen, belum digunakan tegangan pemercepat eksternal sehingga arus berkas elektron yang dibahas/terukur hanya arus yang terbentuk dalam BGP saja (akibat adanya tegangan ADPS) yakni arus IADPS yang besarnya dapat diukur dengan menggunakan alat koil Rogowski.

Besar parameter plasma ditentukan atas dasar besarnya arus plasma lucutan arc $l_{A D P S}$, sedang besar arus plasma lucutan arc I $_{\text {ADPS }}$ dapat diperkirakan akan bergantung pada besar tekanan gas kerja, sehingga memvariasi besar tekanan gas kerja/gas aron untuk memperoleh besar arus plasma (lucutan arc) I IDPS optimum dilakukan pada eksperimen ini. Berdasar pada besar arus pulsa $I_{\text {ADPS }}$ optimum, lebar pulsa, serta bentuk geometri dan ukuran BGP maka besar parameter plasma (kerapatan plasma $n_{e}$, suhu plasma $T_{e}$, panjang Debye $\lambda_{D}$ dan tebal sheath plasma $d_{s}$ ) di dalam BGP dapat ditentukan(8).

\section{METODOLOGI}

Optimasi arus berkas elektron plasma atau arus $I_{\text {ADPS }}$ optimum dalam Bejana Generator Plasma (BGP) perangkat SEKP dilakukan dengan melibatkan penggunaan bahan dan modul peralatan pada sistem SEKP yang meliputi gas kerja/isian gas argon, detektor kevakuman/meter vakum Penning AIMX dengan TIC Instrumen, rangkaian IDPS dan ADPS, Osiloskop/Digital Storage Oscilloscope GDS-1000 Series dan unit komputer/laptop. BGP berada di dalam bejana sistem SEKP, dibuat dari bahan Stainless Steel (SS) 304 bentuk silinder berdiameter $4,00 \mathrm{~cm}$ dan panjang $48,75 \mathrm{~cm}$. Skema Sumber Elektron Katoda Plasma (SEKP) dengan BGP yang berada di dalamnya adalah seperti ditunjukkan pada Gambar 1.

Ditunjukkan pada Gambar 1 bahwa BGP mempunyai dua sistem elektroda pembentuk plasma di sisi kiri dan kanan, dengan grid yang dipasang di dinding BGP bagian bawah yang juga berperan sebagai anoda. Dua buah sistem pembentuk plasma di dalam BGP, yang pertama sistem elektroda (katoda dan anoda pemicu) yang menginisiasi pembentukan lucutan plasma, yang kedua sistem elektroda pelucutan plasma yang membentuk plasma di antara katoda pemicu dengan anoda pemercepat/grid pada dinding BGP. Katoda pemicu berbentuk silinder pejal dari bahan tembaga $\left(C_{u}\right)$ dan anoda pemicu berbentuk kerucut dari bahan SS 304 serta di antara 
katoda dan anoda pemicu dibatasi dengan cincin dari bahan teflon. Plasma yang terbentuk dari dua buah sistem elektroda tersebut akan mengisi ruang di dalam BGP.

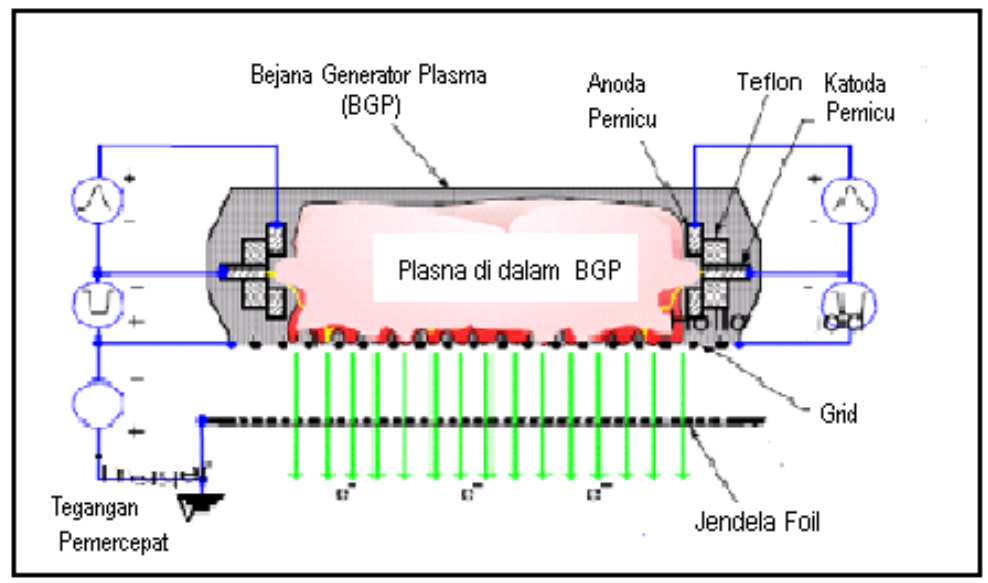

Gambar 1. Skema Sumber Elektron Katoda Plasma (SEKP) dengan BGP di dalamnya.

Optimasi arus berkas elektron di dalam BGP (I ADPS-opt. $\left._{\text {. }}\right)$ dilakukan setelah untuk masing-masing modul peralatan pendukung operasional sistem perkakas SEKP dapat bekerja dengan baik, yang meliputi sistem vakum, sistem elektroda pemicu, sistem sumber daya pembentuk lucutan arc plasma, alat ukur tegangan tinggi (probe pembagi tegangan), alat ukur arus pulsa (koil Rogowski) serta detektor/perekam (Digital Storage Oscilloscope GDS-1000 Series) untuk pulsa arus IDPS dan pulsa arus ADPS.

Pelucutan arus plasma dalam BGP dilakukan dengan mengoperasikan sumber daya tegangan tinggi pulsa $12 \mathrm{kV}$ sistem IDPS (kutub negatip pada katoda dan kutub positip pada anoda pemicu), untuk pembentukan spot plasma. Bila pembentukan spot plasma telah berhasil, langkah selanjutnya adalah dengan mengoperasikan sumber daya tegangan tinggi searah sistem ADPS sebesar $1 \mathrm{kV}(\geq 800 \mathrm{~V})$ pada anoda grid. Bila sistem ADPS dengan tegangan searah sebesar $1 \mathrm{kV}$ telah dipasang pada anoda grid (dinding BGP) dan besar tekanan gas argon dalam BGP telah ditentukan/dipilih pada tekanan yang dikehendaki maka dengan mengoperasikan sistem tegangan pemicu akan diperoleh arus lucut elektron plasma I ADPS (pada tekanan gas argon tertentu).

Optimasi arus $I_{A D P S}$ dilakukan pada tekanan gas kerja/gas argon $P_{\text {Ar }}$ yang divariasi dari tekanan orde $10^{-4}$ yakni $P_{A r}=4,4 \times 10^{-4}$ mbar sampai dengan orde $10^{-3}$ yakni $P_{A r}=\left(24 \times 10^{-4}=2,4 \times 10^{-3}\right)$ mbar, pada keluaran tegangan ignitor sebesar $12 \mathrm{kV}$ (IDPS) dan tegangan anoda pemercepat $1 \mathrm{kV}$. Arus lucut plasma diamati menggunakan Digital Storage Oscilloscope GDS-1000 Series, yang tertayang dalam bentuk pulsa dengan sumbu vertikal/ordinat menunjukkan harga tegangan keluaran $V_{t}$ (volt) dan sumbu horisontal/absis menunjukkan harga lebar pulsa $\tau(\mu \mathrm{s})$. Tekanan gas argon divariasi, sehingga diperoleh besar arus lucut elektron plasma $I_{\text {ADPS }}$ masing-masing pada tekanan gas argon $P_{A r}=4,4 \times 10^{-4} \mathrm{mbar}, P_{A r}=4,4 \times 10^{-4} \mathrm{mbar}, P_{A r}=6,4 \times 10^{-4} \mathrm{mbar}, P_{A r}=$ $8,4 \times 10^{-4}$ mbar dan $P_{A r}=24 \times 10^{-4}$ mbar. Besar arus lucut $I_{A D P S}$ pada tekanan $P_{A r}$ tertentu dapat diukur dengan menggunakan koil Rogowski. Harga parameter koil Rogowski yang digunakan dalam penelitian ditunjukkan pada Tabel 1 (9).

Besar arus lucut spot (sistem IDPS) dan arus lucut berkas elektron plasma (sistem ADPS) di dalam BGP dapat ditentukan dengan menggunakan rumus yang ditunjukkan pada persamaan $(1)^{(10)}$ :

$$
I_{t}=\frac{2 \pi a R C}{\mu A n} V_{t}
$$

dengan $l_{t}=$ besar arus lucut plasma $(\mathrm{A}), a=$ jejari mayor torus $=$ jejari Toroid $(\mathrm{m}), R=$ resistansi integrator $(\Omega), C=$ kapasitan integrator $(\mathrm{F}), \mu=$ tetapan permeabilitas $=\mu_{0} \times \mu_{r}=\left(4 \pi \times 10^{-7}\right) \times \mu_{r}\left(\mathrm{Hm}^{-1}\right), \mathrm{Vt}=$ tegangan terukur (volt), $A=$ luas tampang lintang minor torus/Toroid $\left(\mathrm{m}^{2}\right)$ dan $n=$ jumlah kumparan/liitan torus. 
Table 1. Parameter koil Rogowski

\begin{tabular}{llll}
\hline No. & Parameter & Simbol & Satuan \\
\hline 1 & Dia. luar & $\emptyset_{\text {luar }}$ & $28 \times 10^{-3} \mathrm{~m}$ \\
\hline 2 & Dia. dalam & $\emptyset_{\text {dalam }}$ & $14,24 \times 10^{-3} \mathrm{~m}$ \\
\hline 3 & Dia. tengah & $\emptyset_{\text {tengah }}$ & $21,12 \times 10^{-3} \mathrm{~m}$ \\
\hline 4 & Tebal Toroid & $t_{t}$ & $11 \times 10^{-3} \mathrm{~m}$ \\
\hline 5 & LebarToroid & $\mathrm{Lt}$ & $6,88 \times 10^{-3} \mathrm{~m}$ \\
\hline 6 & Jejari Toroid & $r_{\text {toroid }}$ & $10,56 \times 10^{-3} \mathrm{~m}$ \\
\hline 7 & Dia. kawat kumparan & $\emptyset_{\text {kawat }}$ & $0,4 \times 10^{-3} \mathrm{~m}$ \\
\hline 8 & Jejari kawat kumparan & $r_{\ell}$ & $0.2 \times 10^{-3} \mathrm{~m}$ \\
\hline 9 & Jumlah kumparan & $n$ & 80 lilitan \\
\hline 10 & Tampang lint. Rogowski & $A_{k R}$ & $75,68 \times 10^{-6} \mathrm{~m}$ \\
\hline 11 & Permeabilitas relatif & $\mu_{r}$ & $93 \mathrm{H} / \mathrm{A}$ \\
\hline 12 & Permeabilitas udara & $\mu_{0}$ & $4 \pi \times 10^{-7} \mathrm{H} / \mathrm{A}$ \\
\hline
\end{tabular}

Pada Persamaan (1) karena masing-masing besar harga tetapan dan besaran fisis dapat diketahui maka besar arus lucut $I(t)$ pada arus lucut spot plasma (sistem IDPS) dan arus lucut $I_{\text {ADPS }}$ di dalam BGP dapat ditentukan.

Dengan mengingat muatan 1 (satu) Coulomb untuk partikel elektron adalah sebanyak 6,256 × 1018 buah partikel, maka kalau ukuran BGP diketahui (bentuk silinder berjejari $r$ dan panjang $I$ ), selanjutnya karena besar muatan total $Q$ yang merupakan hasil kali besar arus lucut $I(t)$ dengan lebar pulsa $\tau$ dapat diperoleh dari hasil eksperimen, maka kerapatan partikel elektron $n_{e}$ dalam BGP dapat dihitung menggunakan persamaan (2) :

$$
n_{e}=\frac{\left(6,256 \times 10^{18}\right) Q}{\pi r^{2} l}
$$

Rapat arus lucut elektron plasma dalam BGP yang merupakan arus lucut elektron termal, dapat dinyatakan sebagai:

$$
J_{r}=e n_{e} \sqrt{\frac{k T}{2 \pi m_{e}}}
$$

dengan $e=$ muatan elektron $=1,602 \times 10^{-19} \mathrm{C}, n_{e}=$ kerapatan plasma, $k=$ tetapan Boltzmann $=1,381 \times 10^{-23} \mathrm{~J} / \mathrm{K}$, $T$ = suhu plasma, $m_{e}=$ massa elektron $=9,109 \times 10^{-31} \mathrm{~kg}$. Dari persamaan (3) suhu elektron plasma $T$ dapat dinyatakan sebagai :

$$
T=\frac{2 \pi m_{e} J_{r}^{2}}{e^{2} n_{e}^{2} k}
$$

Tebal selubung/sheat plasma $d_{s}$ oleh Peter Debye telah dikarakterisasi panjang skalanya yang selanjutnya dinamakan panjang Debye $\lambda_{D}$ yang rumusnya dinyatakan pada persamaan (5) :

$$
\lambda_{D}^{2}=\frac{\varepsilon_{0} k T_{e}}{e^{2} n_{e}} \text { atau } \lambda_{D}=743 \sqrt{\frac{T_{e}}{n_{e}}}
$$

dengan $\varepsilon_{0}=$ tetapan permeabilitas $=8,85 \times 10^{-12} \mathrm{As} / \mathrm{Nm}, T_{e}$ dalam satuan $\mathrm{eV}, n_{e}$ dalam satuan $\mathrm{cm}^{-3}$ dan $\lambda_{D}$ dalam satuan $\mathrm{cm}$. Sedang yang dimaksudkan dengan tebal selubung/sheath plasma adalah jarak antara permukaan plasma sampai dengan permukaan BGP (bagian dalam) dinyatakan dengan persamaan (6) sebagai berikut : 


$$
d_{s}=\lambda_{D} \sqrt{\frac{e V}{k T_{e}}}
$$

dengan $\lambda_{D}=$ panjang Debye, $e=$ muatan elektron $=\left(1,602 \times 10^{-19}\right) \mathrm{C}, V=$ besar tegangan terpakai, $k=$ tetapan Boltzmann $=\left(1,381 \times 10^{-23}\right) \mathrm{J} / \mathrm{K}$ dan $T_{e}=$ suhu elektron plasma.

\section{HASIL DAN PEMBAHASAN}

Dari hasil eksperimen pada harga tekanan gas argon $P_{A r}=4,4 \times 10^{-4} \mathrm{mbar}, P_{A r}=6,4 \times 10^{-4} \mathrm{mbar}$ dan $P_{A r}=$ $8,4 \times 10^{-4} \mathrm{mbar}$ dengan bantuan alat ukur koil Rogowski telah diperoleh besarnya arus lucut berkas elektron $I_{\text {ADPS }}$ (bentuk pulsa) yang sama yakni dengan lebar pulsa $\tau=100 \mu$ s dan tegangan terukur $V_{t}=8$ volt. Pada saat tekanan $P_{A r}=14 \times 10^{-4}$ mbar diperoleh besar arus lucut berkas elektron $I_{\text {ADPS }}$ dengan $\tau=100 \mu$ s dan $V_{t}=7,5$ volt dan pada saat $P_{A r}=24 \times 10^{-4}$ mbar diperoleh $I_{A D P S}$ dengan $\tau=100 \mu$ s dan $V_{t}=7$ volt seperti ditunjukkan pada Gambar 2, 3, 4, 5 dan 6.

Berbagai besar arus berkas elektron $I_{A D P S}$ dalam BGP yang sesuai dengan masing-masing harga $P_{A r}$, dapat diperoleh dengan menggunakan persamaan (1) dengan besar tegangan terukur $V_{t}$ (bervariasi bergantung pada besar $P_{\text {Ar }}$, , besaran $a=$ jejari mayor torus $=$ jejari Toroid $=10,56 \times 10^{-3} \mathrm{~m}, R=$ tahanan integrator $=100 \Omega, C=$ kapasitan integrator $=2,2 \times 10^{-6} \mathrm{~F}, \mu=$ tetapan permabilitas, $=\mu_{0} \times \mu_{r}=\left(4 \pi \times 10^{-7}\right)(93) \mathrm{Hm}^{-1}, \quad A=$ luas tampang lintang minor torus $/$ Toroid $=75,68 \times 10^{-6} \mathrm{~m}^{2}$ dan $n=$ jumlah kumparan/lilitan torus $=80$ lilitan.

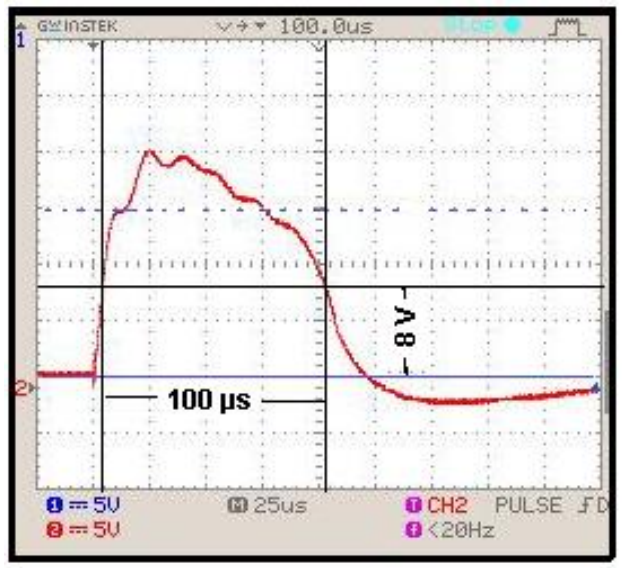

Gambar 2. Pulsa arus $I_{A D P S}\left(\tau=100 \mu \mathrm{s}, V_{t}=8\right.$ volt) pada saat $P_{A r}=4,4 \times 10^{-4} \mathrm{mbar}$.

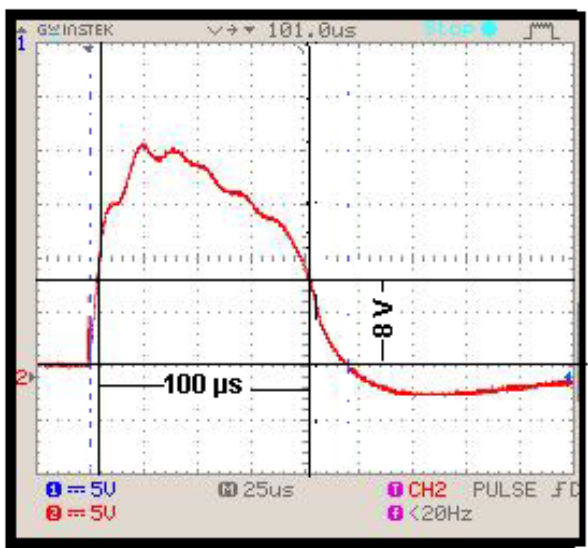

Gambar 3. Pulsa arus $I_{\text {ADPS }}\left(\tau=100 \mu \mathrm{s}, V_{t}=8\right.$ volt $)$ pada saat $P_{A r}=6,4 \times 10^{-4} \mathrm{mbar}$. 


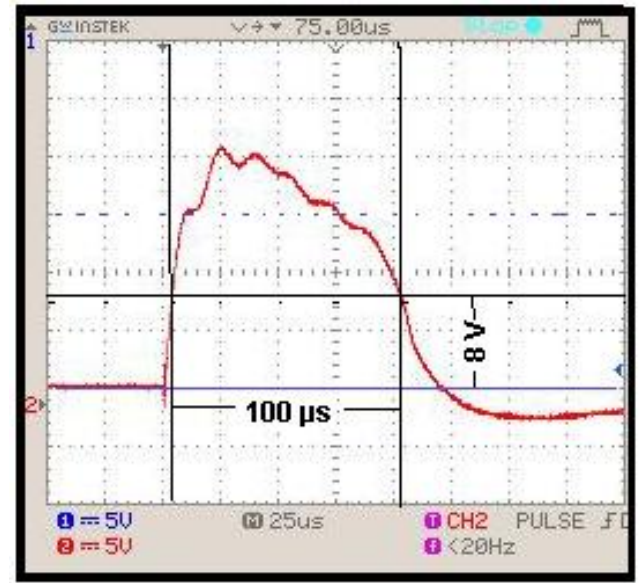

Gambar 4. Pulsa arus $I_{\text {ADPS }}\left(\tau=100 \mu \mathrm{s}, V_{t}=8\right.$ volt $)$ pada saat $P_{A r}=8,4 \times 10^{-4} \mathrm{mbar}$.

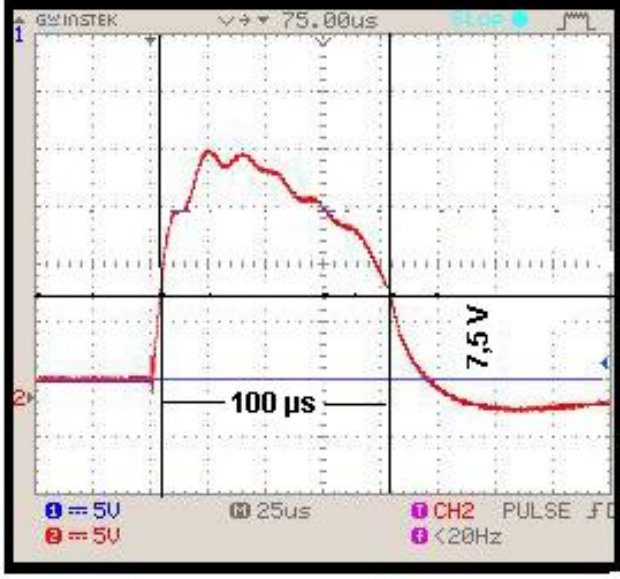

Gambar 5. Pulsa arus $I_{\text {ADPS }}\left(\tau=100 \mu \mathrm{s}, V_{t}=8\right.$ volt) pada saat $P_{A r}=14 \times 10^{-4} \mathrm{mbar}$.

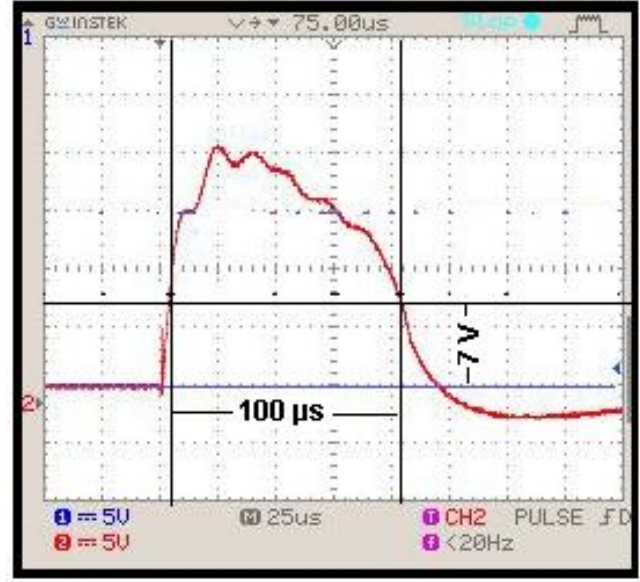

Gambar 6. Pulsa arus $I_{A D P S}\left(\tau=100 \mu \mathrm{s}, V_{t}=8\right.$ volt) pada saat $P_{A r}=24 \times 10^{-4}$ mbar.

Pada Tabel 2 ditunjukkan hasil perhitungan besar arus $I_{A D P S}$ pada berbagai tekanan gas argon $P_{A r}\left(P_{A r}=4,4\right.$ $\times 10^{-4} \mathrm{mbar}, P_{A r}=6,4 \times 10^{-4} \mathrm{mbar}, P_{A r}=8,4 \times 10^{-4} \mathrm{mbar}, P_{A r}=14 \times 10^{-4} \mathrm{mbar}$ dan $P_{A r}=24 \times 10^{-4} \mathrm{mbar}$ ) atas dasar hasil data dari Gambar 2 sampai dengan Gambar 6 . 
Optimasi Arus Berkas Elektron dan Penentuan Harga Parameter Dalam Bejana Generator Plasma (Agus Purwadi)

Tabel 2. Hasil perhitungan besar arus $I_{\text {ADPS }}$ pada berbagai tekanan gas argon $P_{A r}$.

\begin{tabular}{ccccc}
\hline No. & $P_{\text {Ar }}(\mathrm{mbar})$ & $V_{\mathrm{t}}(\mathrm{volt})$ & $\tau(\mu \mathrm{s})$ & $l_{\text {ADPS }}(\mathrm{A})$ \\
\hline 1. & $4,4 \times 10^{-4}$ & 8 & 100 & 164,8 \\
\hline 2. & $6,4 \times 10^{-4}$ & 8 & 100 & 164,8 \\
\hline 3. & $8,4 \times 10^{-4}$ & 8 & 100 & 164,8 \\
\hline 4. & $14 \times 10^{-4}$ & 7,5 & 100 & 154,5 \\
\hline 5. & $24 \times 10^{-4}$ & 7 & 100 & 144,2 \\
\hline
\end{tabular}

Pada Tabel 2 ditunjukkan bahwa besar arus lucut (arc) berkas elektron plasma $I_{A D P S}$ yang diperoleh telah sesuai dengan yang diharapkan (orde ratusan $A$ dengan lebar pulsa $100 \mu \mathrm{s}$ ). Besar arus berkas elektron optimum $I_{\text {ADPS-opt. }}$ terjadi pada $I_{\text {ADPS-Opt. }}=164,8 \mathrm{~A}$ yakni terjadi saat tekanan gas argon $P_{\text {Ar-opt. }}$ pada orde $10^{-4}$ mbar (terjadi pada saat $P_{A r}=4,4 \times 10^{-4} \mathrm{mbar}, P_{A r}=6,4 \times 10^{-4} \mathrm{mbar}$ dan $\left.P_{A r}=8,4 \times 10^{-4} \mathrm{mbar}\right)$. Sedang untuk $P_{A r}$ pada orde $10^{-3}$ mbar (pada $P_{A r}$ semakin besar derajat kevakumannnya, yakni pada $P_{A r}=14 \times 10^{-4} \mathrm{mbar}=1,4 \times 10^{-3} \mathrm{mbar}$ dan $P_{A r}$ $=2,4 \times 10^{-3} \mathrm{mbar}$ ), arus $I_{\text {ADPS }}$ yang diperoleh harganya semakin menurun yakni sebesar $I_{\text {ADPS }}=154,5 \mathrm{~A}$ lalu menjadi $I_{\text {ADPS }}=144,2 \mathrm{~A}$. Penurunan besar arus $I_{\text {ADPS }}$ pada derajat kevakuman yang semakin besar ini dikarenakan dengan semakin besarnya derajat kevakuman maka akan semakin banyak juga partikel $A_{r}$ di dalam BGP sehingga akan menghambat arus berkas elektron $I_{A D P S}$ yang melewati media tersebut. Di samping itu penurunan arus $I_{A D P S}$ tersebut juga karena belum dipasangnya tegangan pemercepat eksternal pada kolektor yang besarnya sekitar $200 \mathrm{kV}$.

Dari hasil $I_{\text {ADPS-opt. }}=164,8$ A dan lebar pulsa $\tau=100 \mu$ s dapat diperoleh besar muatan $Q=I_{\text {ADPS-opt }} \times \tau=$ $\left(1648 \times 10^{-5}\right) \mathrm{C}$. Diketahui bahwa ukuran BGP adalah panjang $I=48,75 \mathrm{~cm}$ dan jari-jari $r=2,00 \mathrm{~cm}$, maka kalau besaran $r, I$ dan $Q$ tersebut disubstitusikan pada persamaan (2) akan diperoleh besar kerapatan elektron plasma dalam BGP sebesar $n_{e}=\left(1,684 \times 10^{20}\right)$ partikel $/ \mathrm{m}^{3}$.

Berdasar pada besar kerapatan arus berkas plasma spot pada sistem SEKP untuk besar jejari berkas arus orde mikrometer adalah $j_{s}=\left(10^{6}-10^{8}\right) \mathrm{A} / \mathrm{cm}^{2(8)}$ serta untuk besar jejari arus berkas elektron hanya sampai dengan $5 \mathrm{~cm}^{(11)}$, maka untuk arus berkas elektron optimum $I_{\text {ADPS-opt. }} \approx 164,8 \mathrm{~A}$ dengan jejari arus berkas $2 \mathrm{~mm}$, dari hasil perhitungan telah diperoleh kerapatan arus plasma sebesar $J_{(r: 2 m m)}=\left(1,312 \times 10^{7}\right) \mathrm{A} / \mathrm{m}^{2}$. Suhu elektron plasma $T_{e}$ dapat ditentukan dengan mensubstitusikan harga kerapatan arus plasma $J_{(r: 2 \mathrm{~mm})}$ dan kerapatan elektron plasma $n_{e}$ $=\left(1,684 \times 10^{20}\right)$ partikel $/ \mathrm{m}^{3}$ pada persamaan (4). Telah dihitung dan diperoleh besar suhu plasma elektron sebesar $T_{e}=\left(9,788 \times 10^{4}\right) \mathrm{K}=8,44 \mathrm{eV}$.

Panjang Debye $\lambda_{D}$ dapat diperoleh dengan mensubstitusikan harga suhu elektron plasma $T_{e}$ dan kerapatan elektron plasma $n_{e}$ ke dalam persamaan (5), telah dihitung dan diperoleh harga $\lambda_{D}=\left(166,337 \times 10^{-6}\right) \mathrm{m}$ $\approx 0,17 \mathrm{~mm}$. Tebal selubung/sheath plasma $d_{s}$ yang merupakan jarak antara permukaan plasma sampai dengan permukaan bagian dalam BGP dapat diperoleh dari Pers. (6) yakni dengan mensubstitusikan besaran $\lambda_{D}=$ $\left(166,337 \times 10^{-6}\right) \mathrm{m}, \mathrm{e}=\left(1,602 \times 10^{-19}\right) \mathrm{C}, \mathrm{V}$ (tegangan terpakai) $=11 \mathrm{kV}, \mathrm{k}=\left(1,381 \times 10^{-23}\right) \mathrm{J} / \mathrm{K}$ dan $T_{e}=(9,788 \times$ $\left.10^{4}\right) \mathrm{K}$, dan setelah dihitung diperoleh harga $d_{s}=\left(6005,764 \times 10^{-6}\right) \mathrm{m} \approx 6,00 \mathrm{~mm}$.

\section{KESIMPULAN}

Pada Bejana Generator Plasma (BGP) yang dibuat dari bahan Stainless Steel (SS) 304 bentuk silinder diameter $4,00 \mathrm{~cm}$ dan panjang $48,75 \mathrm{~cm}$ : Besar arus berkas elektron optimum adalah sebesar $I_{\text {ADPS-opt. }}=164,80 \mathrm{~A}$ tejadi pada tekanan gas argon orde $10^{-4}$ mbar ; Pada tekanan gas argon orde $10^{-3}$ mbar (derajat kevakuman semakin besar), besar arus berkas elektron dalam BGP semakin menurun yakni menjadi $I_{A D P S}=154,50 \mathrm{~A}$ pada $\mathrm{P}_{\mathrm{Ar}}$ $=\left(14 \times 10^{-4}\right)$ mbar dan menjadi $I_{\text {ADPS }}=144,20 \mathrm{~A}$ pada $\mathrm{P}_{\mathrm{Ar}}=\left(24 \times 10^{-4}\right)$ mbar. Penurunan besar arus $I_{\text {ADPS }}$ pada derajat kevakuman yang semakin besar tersebut dikarenakan dengan semakin besarnya derajat kevakuman maka akan semakin besar pula jumlah partikel $A_{r}$ di dalam BGP sehingga akan menghambat besar arus berkas elektron $I_{\text {ADPS }}$ yang melewati media tersebut. Di samping itu penurunan arus $I_{\text {ADPS }}$ tersebut juga karena belum dipasangnya tegangan pemercepat eksternal pada kolektor yang besarnya sekitar $200 \mathrm{kV}$; Saat arus berkas elektron mencapai harga optimum $I_{\text {ADPS-opt. }}=164,80 \mathrm{~A}\left(P_{\mathrm{Ar}}\right.$ orde $\left.10^{-4} \mathrm{mbar}\right)$ besar parameter plasma di dalam BGP 
adalah kerapatan elektron plasma $n_{e}=\left(1,684 \times 10^{20}\right) \mathrm{cacah} / \mathrm{m}^{3}$, suhu elektron plasma $T_{e}=\left(9,788 \times 10^{4}\right) \mathrm{K}=$ $8,44 \mathrm{eV}$, panjang Debye $\lambda_{D} \approx 0,17 \mathrm{~mm}$ dan tebal sheath plasma $d_{s} \approx 6,00 \mathrm{~mm}$.

\section{UCAPAN TERIMA KASIH}

Penulis mengucapkan banyak terima kasih kepada Prof. Drs. Sudjatmoko, S.U., selaku Peneliti Utama dalam kegiatan penelitian SEKP (yang selalu memberikan tugas dan saran-saran dalam rapat rutin koordinasi), serta kepada semua personil yang terlibat dalam kegiatan penelitian SEKP ini (Drs. Widdi Usada, Bambang Siswanto S.Si, Ir. Wiryoadi, Dra. Lely Susita R.M., Drs. Aminus Salam, Drs. Budi Santosa, MT, Saefurrochman, ST, Ihwanul Azis, AMd, Heri Sudarmanto dan Untung Margono) atas segala bantuannya, sehingga penelitian ini dapat diselesaikan. Semoga amal baik Bapak-bapak dan ibu mendapatkan balasan yang setimpal dari Tuhan Allah SWT. Amin.

\section{DAFTAR PUSTAKA}

1. J.Z. GLEIZER, V. VEKSELMAN, S. YATOM, J. FELSTEINER, and Y.E. KRASIK, Radiation Effects \& Defects in Solids, iFirst, (2011) 1-10

2. Y.E. KRASIK, D. YARMOLICH, J.Z. GLEIZER, V. VEKSELMAN, Y. HADAS, V.T. GUROVICH, and J. FELSTEINER, Physics of Plasmas 16, 057103 (2009) 057103-1 - 057103-11

3. J.Z. GLEIZER, Y. HADAS, V.T. GUROVICH, J. FELSTEINER, and Y.E. KRASIK, Journal of Applied Physics 103, 043302 (2008) 043302-1 - 043302-11

4. R. PURWADI, et al., Application of Large Area Plasma Cathode Electron Beam for Natural Rubber Vulcanization, ITAC Ltd., 8-2 Kamisuwa Tsubame City Niigata 959-0181 Niigata, Japan (2010) 497-501

5. E. OKS, Plasma Cathode Electron Sources, Physics, Technology, Applications, Institute of High Current Electronics (IHCE), Russian Academy of Sciences, 2/3 Akademichiscy Ave, 634055 Russia. Translated from Russian by Titiana, Cherkashina and Anna Korovina December (2006) 14-15

6. A.N. KOROLYOV, et al., Design of Compact System With Wide Electron Beam For Radiation Technology. Proceeding of Particle Accelerator Conf. PAC (2001) 30-32

7. E. OKS, Lecture 4 Electron Emission From Plasma, presented in BATAN Accelerator School, Yogyakarta, Indonesia, $5^{\text {th }}$ - $9^{\text {th }}$ December $(2011)$

8. E. OKS, Lecture 2 Low Pressure Discharges For Plasma Electron Sources, presented in BATAN Accelerator School, Yogyakarta, Indonesia, $5^{\text {th }}$ - gth $^{\text {th }}$ December (2011)

9. WIRYOADI, B. SISWANTO, A. PURWADI, L. SUSITA R.M,, SUDJATMOKO, "Sistem Deteksi Spot Plasma Pada Elektoda Ignitor", Prosiding Pertemuan dan Presentasi IImiah Penelitian Dasar Ilmu Pengetahuan dan Teknologi Nuklir, ISSN 0216-3128, PTAPB-BATAN,Yogyakarta, 26 Juni (2013) 66-74

10. A. PURWADI, W. USADA, Rancang Bangun Spark Gap Saklar Sumber Elektron Berbasis Plasma dan Metoda Penentuan Besar Arus Berkas Pulsanya, Prosiding PPI Litdas Iptek Nuklir, PTAPB-BATAN Yogyakarta, Indonesia. 20 Juli (2010) 118-128

11. E. OKS, Lecture 9 Low Energy, High Current Pulsed Electron Beams, presented in BATAN Accelerator School, Yogyakarta, Indonesia, $5^{\text {th }}$ 9 $^{\text {th }}$ December (2011) 